\title{
Development of Student Attendance Reporting System Using WhatsApp Gateway with Android-Based Broadcasting Method
}

\author{
Enjang Ali Nurdin ${ }^{1}$, Wahyudin ${ }^{2}$, Deni Martin ${ }^{3}$ \\ \{enjang_cs@upi.edu' ${ }^{1}$,wahyudin.ilkom@gmail.com² ${ }^{2}$ denim388@gmail.com ${ }^{3}$ \} \\ Department of Computer Science Education, Universitas Pendidikan Indonesia, Bandung, \\ Indonesia $^{1,2,3}$
}

\begin{abstract}
This research study how to convey student attendance to the parents and documentation process by schools about. The purpose of this research is to design and build a student attendance reporting application using WhatsApp gateway for parents to control their kids and can help users in the present process. The development model consists of stages: (1) Listen to the customer, (2) Build revise mock-up, (3) Customer test drive mock-up. Data collection techniques using TAM (Technology Acceptance Model). The results stated that the level of eligibility of student attendance reporting systems reviewed by aspect perceived usefulness is $86 \%$, perceived ease of use is $90 \%$, behavioural intention is $90 \%$, actual use is $90 \%$, attitude toward using is $90 \%$, with an average rating is $89 \%$ and every aspect is in very good category. In conclusion, the student attendance reporting system can help user to make a presence process and worthy for use.
\end{abstract}

Keywords: Student attendance application, WhatsApp gateway, Reporting system

\section{Introduction}

One of the teacher's activity during the class meeting is to record student attendance or commonly called list of presence. Listing presence is an activity of data collection on attendance, part of an activity reporting of an institution, or an institution component itself which consists of attendance lists ordered and arranged in such a way that makes it easy to find and used at any time by interested parties [1]. Student attendance can also be used as a means of information in terms of disciplinary by students' parents to knowing their children's school attendance and thus foster parent's trust and assurance towards the school [2]. Parental and institutional control is crucial in making efforts to prevent student misbehaviour which includes skipping class. Therefore, the help of an information system and technology is currently needed to facilitate parents and school in supervising student attendance real-time as it happens. The consequence of real-time supervision is that students will be reluctant from skipping school since their parents will receive an immediate report on it. Additionally, parents will also know straightaway the attendance development or the attendance level of their children without having to come to school, which is more efficient and effective [3]. Several previous studies that use technology to record student attendance and send it to their parents/caregiver real-time $[3,4]$. 
Based on the research conducted by Cahyono, the author wishes to develop the system further as SMS Gateway technology is considered not economically efficient because school institution has to incur costs on every sent message to parents/caregiver which is not cheap as the number of messages sent is very large. Mobile technology development that is popular these days is android based. Android is an operating system modified from Linux that is used widely from cell phones and tablet to smart tv. The use of the android operating system is spreading among Indonesian people from children to adult. In this case, the author considered to replace SMS Gateway technology with a more economically efficient communication platform such as WhatsApp. WhatsApp is a cross-platform mobile application. Compared to Short Message Service (SMS) which is a paid platform limited to text-based messages only, WhatsApp application is free and has a broader message format ranging from images, videos, and audios in an unlimited amount.

Teacher on duty or picket teacher carries out additional tasks which serve to assist, monitor, and maintain learning activity in school. School picket teacher officers are appointed based on a decree issued by the school principal. Teacher take turns in doing picket duty which is scheduled based on the principal's policy. Each teacher takes duty at least once a week. Picket hour is counted from the first learning hour to the last learning hour. The duty is conducted with at least two teachers according to the school's need and condition.

The six main roles of picket teachers are (1) improving the implementation of $9 \mathrm{~K}$ (safety, cleanliness, order, beauty, solidarity, shade, health, role model, and openness), (2) supervising students, (3) upholding school rules and regulations, (4) conducting data collection, recording, and filling out picket books, (5) assist the disciplinary in teaching and learning activity, and (6) recording picket activity results.

From the six aforementioned roles, the author tackles student attendance as a problem to be researched. An interview conducted to one of the picket teachers in SMK Negeri 8 Bandung shows that picket teacher has a duty to tour the entire classes to record student attendance, starting at 8 o'clock when all students have entered. Aside from informing student attendance to the parents, this application is also expected to facilitate picket teacher in attendance collection process and recap, with which the recap can be delivered to the next party to follow up student attendance.

Basically, all parents expect their children to arrive school safely and to take part in teaching and learning activity as they should, but in reality not a few children departs from home but does not arrive at school due to teenage misbehaviour or unexpected events on the way. Additionally, not every parent can take their children to school due to many factors such as unmatched work time, lack of vehicles, or student's reluctant to be seen with their parents. These are the obstacles for parents to feel assured that their children arrive at school. That limitation enables the student to skip school and not participate in learning activity because they are free from parent's supervision. Therefore, the school should pay attention to real-time monitoring by parents as listing presence is happening.

With attendance listing feature that gives immediate information to parents on the same day will make children more reluctant to skip school because their parents will be informed, which can decrease the probability of student skipping school. Students' presence and absence in school are considered an important issue in school management because it is very closely related to student achievement.

One of the uses of listing attendance includes calculating the possibility of students taking exams $[5,6]$. Retrieval of attendance data done manually has many shortcomings which are a high possibility in lost or damaged data and lack of efficiency and effectiveness in the data processing. There are several types of listing attendance and what distinguishes those are the 
way they are used and the level of usefulness. In general, the types of attendance can be grouped into two, namely: (1) Manual attendance, is a way to list attendance by using a pen (signature). (2) Non-manual attendance is a way to list attendance using computerized tools and systems, such as barcodes, fingerprints, installing NIP, and so on.

This research was conducted at SMK Negeri 8 Bandung with the consideration that the school still uses manual attendance listing. Based on the background problems described above, to find out whether the application of picket teachers can be helped and can provide information about the presence of children in school to parents, the author conducted a study entitled "Development of Student Attendance Reporting System Using WhatsApp Gateway with Android-Based Broadcasting Method".

\section{Research Method}

The research flow that had been conducted were problem formulation, literature study, the application development process using Java, user testing, and report documentation. Data collection technique used is TAM (Technology Acceptance Model) with five aspects, namely (1) perceived usefulness, (2) perceived ease of use, (3) behavioural intention, (4) actual use, and (5) attitude toward using with rating-scale calculation method. The results of this study are as follows: (1) perceived usefulness with score of $86 \%$ and Excellent category, (2) perceived ease of use with score of $90 \%$ and Excellent category, (3) behavioural intention with score of $90 \%$ with Excellent category, (4) actual use with score of $90 \%$ and excellent category, (5) attitude toward using with score of $90 \%$ and Excellent category. The calculation result is used to determine the application's quality and to know if the application can help picket teachers' duty in listing student attendance in SMK Negeri 8 Bandung.

\section{Result and Discussion}

Attendance Management Information System with WhatsApp gateway is developed using Java programming language in Android Studio and firebase for storing the online database.

\subsection{Interface}

Below is the interface design based on a mock-up made prior. Figure $\mathbf{1}$ is the initial display when the application is started. There is a description of the day, date, and year. There is also a button to start presence, see data, and semester recap that functions according to their respective purpose.

Display of class options. Figure 2 is the display when 'Mulai Presensi' button is pressed. In this display, the teacher chooses which class' attendance will be checked. The round button on the right will turn green when the class is already checked. 


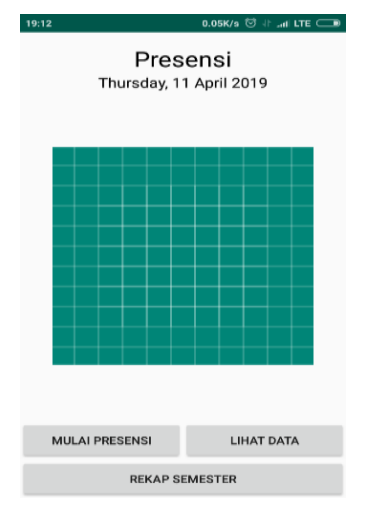

Fig. 1. is the initial display of attendance application

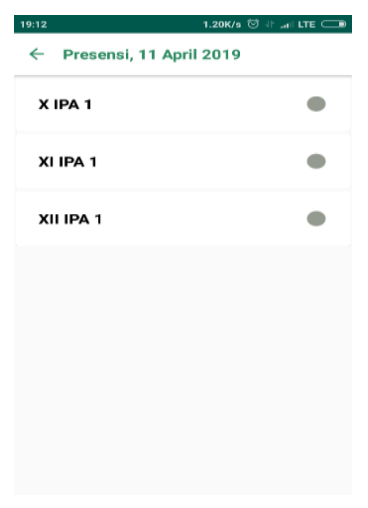

Fig. 2. Class option display

Student list display. On Figure 3 displayed student names. In this page, the information of homeroom teacher and date is also displayed, aside from student's full list with default presence status to make listing easier. If a student is absent, the teacher only has to press the radio button on the absent column, and then a menu of information that can be selected (sick, permission, without information) will appear. The selected information will appear in the information column. After finished, press "save" then the message will be sent to the parents and attendance data saved to the database.

Initial Display of Viewing Data Menu. Figure 4 is the interface when the user pressed the View Data menu. User can choose which date and class' daily recap to be displayed.

Students' Daily Recap View. Figure 5 shows students' class attendance recap based on class and date chosen prior. This page presents class' description, such as its homeroom teacher, date, and attendance recap.

Initial display of Semester Recap menu. Figure 6 shows the page to which the Semester Recap button leads. In this view, the user can choose which class and semester's recap is to be viewed. 


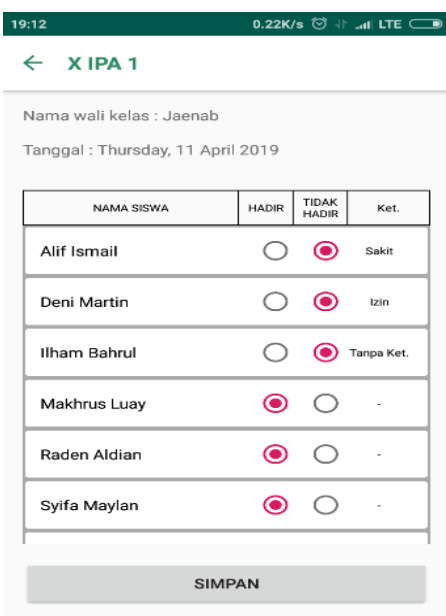

Fig. 3. Students Name List Display

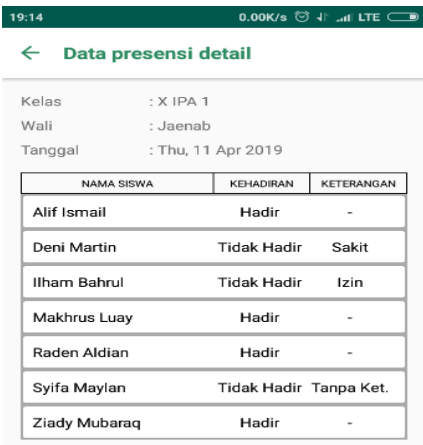

Fig. 5. Students' daily data recap

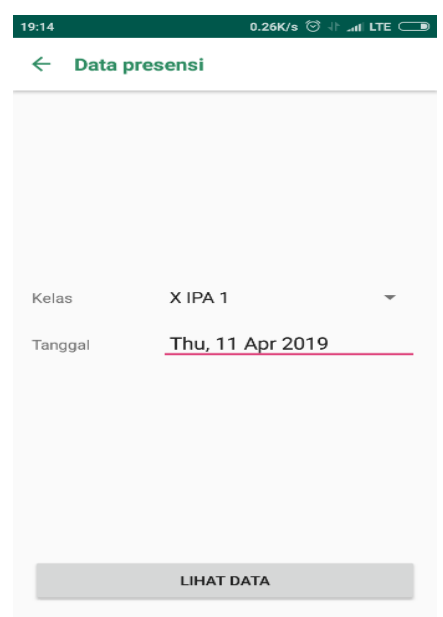

Fig. 4. Initial display of View Data menu

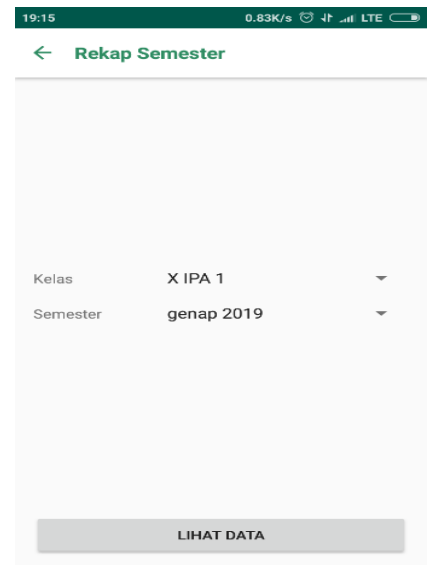

Fig. 6. Initial display of Semester Recap menu

Semester Recap page. Figure 7 shows students' attendance recap based on selected class and semester in the prior page. This page contains homeroom teacher information, date, and the sum of present and absent students throughout the whole semester. The 'send message' button on the right will immediately send a report to student's parents consisting of summary and dates of their child absence, as for 'Print Recap' button will export attendance data to excel format, therefore, enabling the user to print. 


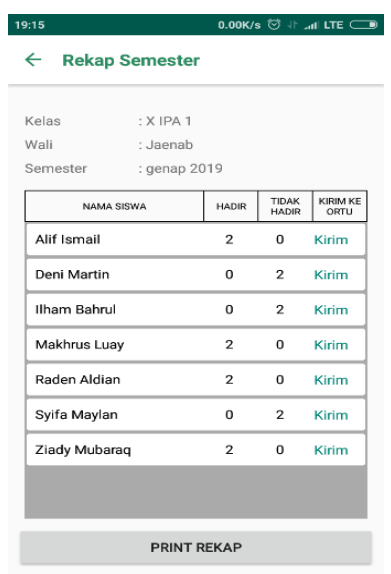

Fig. 7. Semester data recap

\subsection{Message content format for parents}

Message content format for parents contains absence information and semester attendance recap. The examples for the content messages were illustrated in Figure 8 and Figure 9.

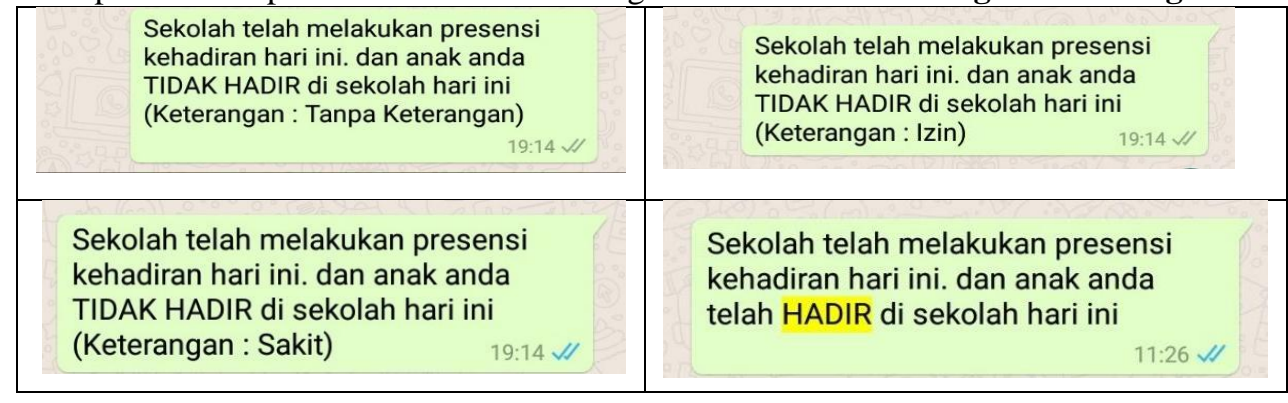

Fig. 8. Message content for absence information

Anak anda yang bernama Deni Martin
kelas X IPA 1 tidak masuk sekolah
2 kali pada tanggal 10-04-2019,
11-04-2019

Fig. 9. Message content of student's semester recap

\section{Discussion and Result}

Before conducting this study, the author spreads questionnaire regarding user requirements for an attendance reporting system to teachers. As much as 22 teachers consists of picket teachers, subject teachers, and homeroom teachers who are the ultimate user for 
attendance reporting system fills the questionnaire which results in the following: (1) $90 \%$ out of 22 respondents needed an android-based attendance system; (2) 100\% respondents agree to create the application.

After user requirements questionnaire is spread out and gained positive feedback from 22 teachers, application sample is developed using prototyping method and gained assessment result in all aspects with Very Good category with details as follows: (1) Perceived Usefulness with $86 \%$ score indicating the system is useful in doing its designed functions; (2) Perceived Ease of Use with $90 \%$ score indicating user's feel of ease while using the system; (3) Behavioral Intention Use with $90 \%$ score indicating users are inclined to continue the use of the system and share it with other schools; (4) Actual Use with $90 \%$ score indicating the system is used to run its designed functions; (5) Attitude Toward Using with $90 \%$ score indicating users favour towards the developed system.

The results of all the aspects are merged and then converted to a scale. The conversion result can be seen in Figure 10. Based on the table and the figure, the attendance reporting system falls in Very Good category with an average score of $89 \%$.

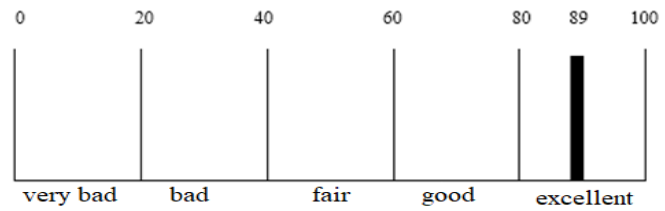

Fig. 10. The conversion result

Aside from ease in listing attendance, the teacher also gets ease in informing parents with the application's feature and gained positive response from parents.

Therefore, based on the study result supported by theories and prior study results, it is safe to conclude that Development of Student Attendance Reporting System Using Whatsapp Gateway with Android-Based Broadcasting Method study can elevate teacher's performance in doing attendance data recap and reporting it to their students' caregiver.

\section{Conclusion}

Based on the study results, Android-based attendance application developed using prototyping method is managed to be made according to user requirements and each step in prototyping method helps author and user to create the application as we wish, with explanation: (1) Listen to Customer: author and users can communicate to solve the app formulation to complete its functions; (2) Build Revize Mock-Up: application is made according to users wish; (3) Customer Test-drive Mock-up: users try the application. If there are any shortcomings or user wishes to add more feature, then the process goes back to step one. With this method, the author is more at ease in communicating with users and to create the application as they wished.

Based on system assessment result, the details are as follows: (1) Perceived Usefulness with $86 \%$ score indicating the system is useful in doing its designed functions; (2) Perceived Ease of Use with $90 \%$ score indicating user's feel of ease while using the system; (3) Behavioral Intention Use with $90 \%$ score indicating users are inclined to continue the use of the system and share it with other schools; (4) Actual Use with $90 \%$ score indicating the 
system is usable to run its designed functions; (5) Attitude Toward Using with $90 \%$ score indicating users favour towards the developed system.

The results of all the aspects are merged and then converted to a scale. The conversion result figure can be seen below. Based on the table and the figure, the attendance reporting system falls in Very Good category with an average score of $89 \%$. It is safe to say that the developed application falls on the Very Good category and is usable for its purpose as well as gained positive feedback from users.

\section{References}

[1] Arulogun, O. T., Olatunbosun, A., Fakolujo, O. A., \& Olaniyi, O. M.: RFID-based students attendance management system. International Journal of Scientific \& Engineering Research, 4(2), 19. (2013)

[2] Adams, K. S., \& Christenson, S. L.: Trust and the family-school relationship examination of parent-teacher differences in elementary and secondary grades. Journal of school psychology, 38(5), 477-497. (2000)

[3] Borale, S. D., Chaudhari, M. P. G., Patil, M. V. B., Shingne, M. A. D., \& Dhoot, G. N.: Fingerprint based attendance management system with SMS alert to parents. In Int J Res Adv Technol (IJRAT)(E-ISSN: 2321-9637) Special issue national conference convergence (pp. 06-07). (2016)

[4] Jaikumar, K., Kumar, M. S., Rajkumar, S., \& Sakthivel, A.: Fingerprint based student attendance system with SMS alert to parents. Int. J. Res. Eng. Technol, 4(2), 293-297. (2015)

[5] Aucejo, E. M., \& Romano, T. F.: Assessing the effect of school days and absences on test score performance. Economics of Education Review, 55, 70-87. (2016)

[6] Dey, I.: Class attendance and academic performance: A subgroup analysis. International Review of Economics Education, 28, 29-40. (2018) 